\title{
Amino Acid Content of Rabbit Urine and Plasma ${ }^{1}$
}

\author{
WALTER D. BLOCK AND RICHARD W. HUBBARD \\ From the Department of Dermatology, Medical School, University of Michigan. \\ Ann Arbor, Michigan \\ Received September 11, 1961
}

\begin{abstract}
The content of amino acids in plasma and urine from male albino rabbits was delermined by ion-exchange chromatography and compared to values for other species.

In general, the amino acids present in the plasma and urine of rabbits are those commonly found in other species. In contrast to human urine in which the content of histidine is usually greater than the two methylated dcrivatives, the content of histidine in rabbit urine is lower than either 1-methylhistidine or 3-methylhistidine. The plasma amino acid pattern is unusual in that glycine content is higher than alanine content; this is the reverse of the pattern in man and the eat.

Fasting the rabbits for $88 \mathrm{hr}$. caused approximately a $66 \%$ decrease in the total amount of urinary amino acids. A 12- or 88-hr. fast caused the plasma total amino acid content to decrease approximately $30 \%$. Valine, isolencine, and leucine contents of the plasma, however, were increased.
\end{abstract}

\section{INTRODLCTION}

Other than the work of Duchateau and Florkin (1) who used microbiological methods to determine the content of 15 amino acids in plasma from normal rabbits, and of Engel and Pollak (2) who used paper chromatography to determine the pattern of amino acids in rabbit serum, information on the quantitative distribution of amino acids in biological fluids of normal rabbits does not appear to be available. The purpose of this investigation was to determine the content of amino acids in the urine and plasma of normal rabbits by means of ionexchange chromatography, and to compare the values to those found in other species.

\section{EXPERIMENTAL}

\section{Animals and Ration}

Albino male rabbits weighing at least $3 \mathrm{~kg}$. were housed individually and fed whole oats and fresh cabbage. With this ration, unlike many of the commercial rations, the rabbit produces an acid

${ }^{1}$ Supported in part by a grant (RG-4794 C4) from the National Institutes of Health, Public Health Service, Bethesda, Maryland. urine, free of undesirable sediment. The animals had access to water at all times.

\section{Collection of Urine and Blood}

Eight rabbits who had received the ration for a minimum of 4 days were placed into individual metabolism cages. Urine collections were made daily on six of the animals (phenol prescrvative), and refrigerated. Three or four consecutive 24-hr. samples for each animal were pooled, ind aliquots frozen. Three of the alove rabbits were then fasted for $88 \mathrm{hr}$. Urine collections were made as before.

Blood was withdrawn from the marginal vein of the ar of three of the ahove rabbits while they were receiving the ration, and from five who had been fasted for $12 \mathrm{hr}$. Thrce of these latter animals were fasted an additional $76 \mathrm{hr}$. (total hours of fasting, 88) and blood was again withdrawn. Plasma was separated by centrifugation.

\section{Chemical Methods}

Urine was prepared for amino acid analysis by the method of Stein (3). Plasma was prepared for analysis by the method of Stein and Moore (4). Amino acids and other ninhydrin-reacting substances in the samples were determined by the quantitative ion-exchange chromatographic method of Spackman, Stcin, and Moore (5). Unknown peaks 1 and 2 in Tables $\mathrm{T}$ and III refer to com- 
TABLE I

Free Amino Acids in the Urine of Male Rabbits Fed an Oats and Cabbage Ration or FASTED FOR 88 HoURS

\begin{tabular}{|c|c|c|}
\hline Amino acid & Ration" & Fasted $^{b}$ \\
\hline & $m g . / 2+k r$. & $m g . / 24 \mathrm{hr}$. \\
\hline Unknown peak 1 & $1.8 \pm 0.8$ & $-c$ \\
\hline Unknown peak 2 & $9.3 \pm 3.2$ & $3.2 \pm 1.1$ \\
\hline Taurine & $15.6 \pm 9.8$ & $7.4 \pm 11.1$ \\
\hline Aspartic acid & $0.6 \pm 0.3$ & $<0.3$ \\
\hline Threonine & $1.0 \pm 0.2$ & $0.5 \pm 0.2$ \\
\hline Serine & $2.6 \pm 0.7$ & $1.0 \pm 0.2$ \\
\hline $\begin{array}{l}\text { Asparagine plus glu- } \\
\text { tamine }\end{array}$ & $2.4 \pm 0.8$ & $1.0 \pm 0.4$ \\
\hline Sarcosine & $2.0 \pm 1.4$ & $<0.3$ \\
\hline Proline & $0.8 \pm 0.4$ & $<0.3$ \\
\hline Glutamic acirl & $2.1+0.9$ & $0.6+0.2$ \\
\hline Citrulline & $0.6 \pm 0.3$ & $<0.3$ \\
\hline Glycine & $7.3 \pm 2.4$ & $1.0 \pm 0.4$ \\
\hline Alanine & $2.5 \pm 1.4$ & $0.6 \pm 0.2$ \\
\hline Valine & $0.3 \pm 0.1$ & $<0.3$ \\
\hline Crstine & $0.7 \pm 0.2$ & $<0.3$ \\
\hline Cystathionine & $1.1 \pm 0.4$ & - \\
\hline Methionine & $0.8 \pm 0.1$ & $<0.3$ \\
\hline Isoleucine & $0.8 \pm 0.4$ & $<0.3$ \\
\hline Leucine & $0.8 \pm 0.4$ & $<0.3$ \\
\hline Tyrosine & $0.7 \pm 0.3$ & $<0.3$ \\
\hline Phenylalanine & $0.8 \pm 0.2$ & $<0.3$ \\
\hline$\beta$-Alanine & $3.2 \pm 0.6$ & 一 \\
\hline $\begin{array}{l}\beta \text {-Aminoisobutyric } \\
\text { acid }\end{array}$ & $1.0 \pm 0.5$ & - \\
\hline Ornithine & $1.9 \pm 0.8$ & $1.2 \pm 1.1$ \\
\hline Ethanolamine & $1.9 \pm 0.9$ & $0.4 \pm 0.1$ \\
\hline Lysine & $3.0 \pm 1.2$ & $1.5 \pm 1.3$ \\
\hline 1-Methylhistidine & $9.8 \pm 2.7$ & $5.9 \pm 2.9$ \\
\hline Histidine & $0.7 \pm 0.2$ & $0.4 \pm 0.1$ \\
\hline 3-Methylhistidine & $3.7 \pm 0.9$ & $1.6 \pm 0.9$ \\
\hline Arginine & $1.2 \pm 0.9$ & $0.4 \pm 0.1$ \\
\hline Total of meansid & 81.0 & 26.7 \\
\hline
\end{tabular}

"Mean \pm S.D. for six animals; a total of twenty-one 24 -hr. collections were made.

$b$ Mean \pm S.D. for three animals; a total of nine 24-hr. collections were made.

- Value not obtained for technical reason.

"Values of $<0.3$ are not included in the total.

pounds eluted in the same chromatographic positions as phosphoserine plus eysteic acid, and phosphoethanolamine from standard amino acid solutions by Spackman et al. (5) and this laboratory.

\section{RESULTS}

\section{Urinary Amivo Acins}

Table I lists the amounts of 30 amino acids and other ninhydrin-reacting substances in the urine of male albino rabbits. Amounts of amino acids cxcreted ranged from $15.6 \pm 9.8 \mathrm{mg}$. taurine to $0.3 \pm 0.1$ mg. valine per $24 \mathrm{hr}$. by the animals fed the oats and cabbage ration. In decreasing order, taurine, 1-methylhistidine, unknown peak 2, glycine, and 3-methylhistidine accounted for approximately $56 \%$ of the amino acids in the urine.

If the animals were fasted for $88 \mathrm{hr}$, the amount of amino acids excreted decreased to approximately one-third of the nonfasting value. Taurine was still the highest in amount $(7.4 \pm 11.1 \mathrm{mg}$.$) , while a$ number of amino acids were excreted in quantities of less than $0.3 \mathrm{mg} .24 \mathrm{hr}$. (Table I). Taurine, 1-methylhistidine, unknown peak 2, 3-methylhistidine, and lysine, in decreasing order, accounted for approximately $73 \%$ of the amino acids in the fasting urine.

\section{Plasma Amino Acids}

Twenty-six amino acids and other ninhydrin-reacting substances were determined in the plasma of the rabbits (Table II). Amounts of amino acids ranged from 14.95 $\pm 5.08 \mathrm{mg}$. asparagine plus glutamine to $0.16 \pm 0.06 \mathrm{mg}$. aspartic acid per $100 \mathrm{ml}$. plasma from animals fed the oats and cabbage ration. In decreasing order, asparagine plus glutaminc, glycine, proline, lysine, alanine, and arginine accounted for approximately $66 \%$ of the amino acids in the plasma.

If the animals were fasted for $12 \mathrm{hr}$., the amount of amino acids in the plasma decreased to approximately $69 \%$ of the nonfasting value. Prolongation of the fasting to 88 hr. caused loss than a $5 \%$ further decrease. The asparagine plus glutamine moiety was still the most abundant in the plasma, $9.58 \pm 2.32 \mathrm{mg}$. and $10.51 \pm 1.08$ $\mathrm{mg}$. per $100 \mathrm{ml}$., rospectively, for animals fasted 12 and 88 hr. These two amino acid derivatives along with glycine, alanine, lysine, arginine, and proline accounted for nearly $60 \%$ of the amino acids in the plasma of rabbits fasted for 12 and $88 \mathrm{hr}$. 
TABLE II

Free Amino Acids in the Plasma of Male Rabbits Fed an Oats and Cabbage Ration, Fasted for 12 Hours and for 88 Holns

\begin{tabular}{|c|c|c|c|}
\hline \multirow{2}{*}{ Amino acid } & \multirow{2}{*}{ Ration $^{a}$} & \multicolumn{2}{|c|}{ Fasted } \\
\hline & & $12 \mathrm{hr}^{6}$ & $88 \mathrm{hrr}^{\mathrm{c}}$ \\
\hline & $m g . / 100 \mathrm{ml}$ & $m g . / 10 \% \mathrm{ml}$ & $m_{g} / 100 \mathrm{hr}$. \\
\hline Taurine & $1.04 \pm 0.32$ & $0.84 \pm 0.45$ & $0.87 \pm 0.37$ \\
\hline Hydroxyproline & $0.48 \pm 0.02$ & $0.22 \pm 0.24$ & $0.27 \pm 0.05$ \\
\hline Aspartic acid & $0.16 \pm 0.06$ & $0.16 \pm 0.18$ & $0.09 \pm 0.01$ \\
\hline Threonine & $1.43 \pm 0.32$ & $1.18 \pm 0.37$ & $1.17 \pm 0.11$ \\
\hline Serine & $3.45 \pm 0.76$ & $2.12 \pm 0.42$ & $1.71 \pm 0.10$ \\
\hline $\begin{array}{l}\text { Asparagine plus } \\
\text { glutamine }\end{array}$ & $14.95 \pm 5.08$ & $9.58 \pm 2.32$ & $10.51 \pm 1.08$ \\
\hline Proline & $4.39 \pm 0.87$ & $2.33 \pm 0.63$ & $2.42 \pm 0.72$ \\
\hline Glutamic acid & $1.60 \pm 0.33$ & $1.43 \pm 0.92$ & $0.75 \pm 0.10$ \\
\hline Citrulline & $2.16 \pm 0.53$ & $1.95 \pm 0.64$ & $0.84 \pm 0.04$ \\
\hline (ilycine & $14.70 \pm 3.45$ & $6.64 \pm 0.38$ & $4.66 \pm 0.16$ \\
\hline Alanine & $3.91 \pm 0.68$ & $4.37 \pm 1.26$ & $3.13 \pm 0.78$ \\
\hline Valine & $1.59 \pm 0.12$ & $1.81 \pm 0.39$ & $2.04 \pm 0.12$ \\
\hline Cystine & $0.92 \pm 0.37$ & $0.48 \pm 0.34$ & $1.34 \pm 0.23$ \\
\hline Cystathionine & $0.23 \pm 0.10$ & $0.20 \pm 0.15$ & $0.17 \pm 0.04$ \\
\hline Methionine & $0.65 \pm 0.07$ & $0.39 \pm 0.21$ & $0.54 \pm 0.11$ \\
\hline Isoleucine & $0.74 \pm 0.40$ & $0.83 \pm 0.14$ & $1.07 \pm 0.22$ \\
\hline Leucine & $1.31 \pm 0.42$ & $1.18 \pm 0.13$ & $1.50 \pm 0.34$ \\
\hline Tyrosine & $1.56 \pm 0.25$ & $1.06 \pm 0.25$ & $0.88 \pm 0.12$ \\
\hline Phenylalanine & $1.05 \pm 0.70$ & $1.10 \pm 0.24$ & $0.83 \pm 0.09$ \\
\hline Ornithine & $2.48 \pm 0.85$ & $1.65 \pm 0.11$ & $1.59 \pm 0.11$ \\
\hline Ethanolamine & $\omega^{d}$ & $0.08 \pm 0.02$ & $0.06 \pm 0.05$ \\
\hline Iysine & $+.04+0.93$ & $3.49+1.03$ & $3.76+0.54$ \\
\hline 1-Methylhistidine & $0.35 \pm 0.07$ & $0.29 \pm 0.12$ & $0.53 \pm 0.23$ \\
\hline Histidine & $1.54 \pm 0.28$ & $1.22 \pm 0.22$ & $1.40 \pm 0.24$ \\
\hline 3-Methylhistidine & $0.25 \pm 0.10$ & $0.34 \pm 0.06$ & $0.60 \pm 0.19$ \\
\hline Arginine & $3.83 \pm 0.56$ & $2.77 \pm 0.51$ & $2.42 \pm 0.38$ \\
\hline Total of means & 68.81 & 17.71 & 15.15 \\
\hline
\end{tabular}

"Mean \pm S.D. for three animals.

$\checkmark$ Vean \pm S.D. for five animals.

Mean \pm S.D. for three animals.

${ }^{d}$ Value not obtained for technical reason.

Although the total amount of amino acids in the plasma decreased during fasting, most of this decrease was eaused by lower levels of eight of the amino acids: serine, asparagine, and glutamine; glutamic acid; citrulline; glycine; tyrosine; ornithine; and arginine. Glycine showed the greatest decrease. The content of valine, cystine, isoleucine, leucine, 1-methylhistidine, and 3methylhistidine was increased by the 88 -hr. fast.

\section{DISCUSSION}

The amino acid content of urine from rabbits fed the oats and cabbage ration, and of plasma from rabbits fasted $12 \mathrm{hr}$. are presented for comparison with values for those of human subjects $(4,6,7)$ and the cat (8) in Table III. To our knowledge, these are the only other mammals in which comparable studies of the urinary and plasma amino acids have been done. In general, the amino acids usually found in the urine and plasma of man and the cat are also present in the urine and plasma of rabbits, although the amounts differ among the species.

Except for $\beta$-alanine, considerably lower amounts of each of the amino acids are 
TABLE III

Content of Free Amino Aoids in Urine and Plasma of Rabbits and Otuer Mammats

\begin{tabular}{|c|c|c|c|c|c|c|}
\hline \multirow{2}{*}{ Amino acid } & \multicolumn{2}{|c|}{ Urine } & \multicolumn{4}{|c|}{ Plasma } \\
\hline & $\mathrm{Rabbit}^{a}$ & Human $^{b}$ & Rabbit $^{c}$ & $\mathrm{Cat}^{d}$ & $\mathrm{Male}^{e^{\mathrm{Hu}}}$ & Female $f$ \\
\hline & \multicolumn{2}{|c|}{$m g . / 24 \mathrm{hr}}$. & \multicolumn{4}{|c|}{$m g . / 100 \mathrm{mll}}$. \\
\hline Unknown peak 1 & 1.8 & 5.3 & & & & \\
\hline Unknown peak 2 & 9.3 & 29.5 & & & & \\
\hline Taurine & 15.6 & 77.8 & 0.84 & 0.7 & 0.55 & 1.06 \\
\hline Hydroxyproline & & & 0.22 & & & \\
\hline Aspartic acid & 0.6 & 6.5 & 0.16 & 0.1 & $<0.03$ & 0.05 \\
\hline 'l'hreonine & 1.0 & 18.3 & 1.18 & 1.4 & 1.39 & 1.36 \\
\hline Serine & 2.6 & 42.8 & 2.12 & 2.1 & 1.12 & 1.25 \\
\hline $\begin{array}{l}\text { Asparagine plus } \\
\text { glutamine }\end{array}$ & 2.4 & 79.0 & 9.58 & & & \\
\hline Sarcosine & 2.0 & 2.3 & & & & \\
\hline Proline & 0.8 & & 2.33 & 2.3 & 2.30 & 1.42 \\
\hline Glutamic acid & 2.1 & 3.8 & 1.43 & 1.8 & 0.70 & 0.59 \\
\hline Citrulline & 0.6 & & 1.95 & $<0.1$ & & \\
\hline Glycine & 7.3 & 126.6 & 6.64 & 2.3 & 1.54 & 1.70 \\
\hline Alanine & 2.5 & 14.4 & 4.37 & 7.0 & 3.41 & 2.48 \\
\hline Valine & 0.3 & 3.3 & 1.81 & 2.4 & 2.88 & 2.11 \\
\hline Cystine & 0.7 & 6.8 & 0.48 & 0.4 & 1.18 & 0.79 \\
\hline Cystathionine & 1.1 & 20.5 & 0.20 & & & \\
\hline Methionine & 0.8 & 4.2 & 0.39 & 0.4 & 0.38 & 0.24 \\
\hline Isoleucine & 0.8 & 3.0 & 0.83 & 0.8 & 0.89 & 0.67 \\
\hline Leucine & 0.8 & 6.8 & 1.18 & 1.6 & 1.69 & 1.17 \\
\hline Tyrosine & 0.7 & 17.1 & 1.06 & 0.7 & 1.03 & 0.66 \\
\hline Phenylalanine & 0.8 & 10.0 & 1.10 & 0.9 & 0.84 & 0.73 \\
\hline$\beta$-Alanine & 3.2 & 3.8 & & $<0.03$ & & \\
\hline$\beta$-Aminoisobutyric acid & 1.0 & 43.7 & & $<0.04$ & & \\
\hline Ornithine & 1.9 & 1.9 & 1.65 & 0.2 & 0.72 & 0.44 \\
\hline Ethanolamine & 1.9 & 11.6 & 0.08 & $<0.04$ & & \\
\hline Lysine & 3.0 & 22.4 & 3.49 & 2.8 & 2.72 & 1.41 \\
\hline 1-Methylhistidine & 9.8 & 39.0 & 0.29 & $1 . t$ & $<0.11$ & \\
\hline Histidine & 0.7 & 110.1 & 1.22 & 1.4 & 1.15 & 0.82 \\
\hline 3-Methylhistidine & 3.7 & 32.5 & 0.34 & 0.1 & $<0.08$ & \\
\hline Arginine & 1.2 & 3.0 & 2.77 & 1.4 & 1.51 & 0.58 \\
\hline
\end{tabular}

"Fed oats and cabbage ration.

${ }^{b}$ Hubbard et al. (6).

C Fasted for $12 \mathrm{hr}$.

d Tallan et al. (8).

estein and Moore (4).

$f$ Soupart (7).

excreted in 24 hr. by the rabbit than by human beings. The pattern between the two species also differs. Taurine, 1-methylhistidine, unknown peak 2 , and glycine, in decreasing order, are the four most abundant amino acids in rabbit urine; while glycine, histidine, asparagine plus glutamine, and taurine are the four most abundant in human urine.

The rabbit has a mean exeretion of his- tidine of $0.7 \mathrm{mg}$. which is lower than the amounts of 1-methylhistidine $(9.8 \mathrm{mg}$.) and 3-methylhistidine $(3.7 \mathrm{mg}$.) excreted. This is the reverse of the finding in man who excretes more histidine (110.1 mg.) than either 1-methylhistidine (39.0 mg.) or 3-methylhistidine (32.5 mg.) (Table III). Little is known of the origin of the methylated derivatives of histidine in urine except for the work of Brown et al. (9) who 
found labeled 1-methylhistidine in urine from monkeys and human subjects given uniformly labeled histidine- $\mathrm{C}^{\mathbf{1 4}}$. No labeled 1-methylhistidine was found in the urine of rats given L-histidine-2-C ${ }^{14}$. Fink et al. (10), and MeManus (11) have reported that 1-methylhistidine excretion is increased in vitamin E-deficient rabbits. The consensus is that increased excretion of methylhistidine might be related to abnormal metabolism of anserine or carnosine which may liave important roles to play in the proper functioning of the muscle. In this laboratory it has been found that more 1methylhistidine than histidine is excreted by a high percentage of paticnts with psoriasis (6). Also, the urinary ratio of $3-$ methylhistidine to histidine is abnormally high in many of thesc patients.

Further studies of listidine metabolism in the normal rabbit, who has a urinary pattern of histidine and methylated histidine excretion similar to many of the human subjects with psoriasis, may lead to information of the metabolic pathway by which these methylated derivatives of histidine arise in the urine.

Citrulline, glycine, ornithine, lysine, and arginine occur in appreciably higher amounts in rabbit plasma than in cat plasma; serine, glutamic acid, glycine, alanine, ornithine, lysine, and arginine values are considerably higher than in human plasma (Table III). The most striking difference among these is in glycine; plasma from rabbits contained a mean of $6.64 \mathrm{mg}$., while cat plasma contained $2.3 \mathrm{mg}$, and human plasma $1.54-1.70 \mathrm{mg} . / 100 \mathrm{ml}$. The amounts of the other amino acids determined in rabbit plasma are either lower or approximately the same as those in cat and human plasma.

The pattern of amino acids in the plasma differs among the three species in that glycine content exceeds alanine in the rabbit. This is not true for man or the cat. If one disregards the asparagine plus glutamine moiety of plasma because values for only the rabbit are available, glycine, lysine, alanine, proline, and arginine, in decreasing order, are the five most abundant amino acids in rabbit plasma. Alanine, lysine, valine, proline, and serine are most abundant in cat plasma; and alanine, valine, lysine, glycine, and proline in human plasma.

That fasting may cause an increase in the branched-chain amino acids of the plasma has been reported by Swendseid et al. (12) for one human subject fasted for 14 days, and by Charkey et al. (13) for six human subjects fasted for 2 days. The present study confirms this finding in another species, the rabbit; valine, isoleucine. and leucine content of the plasma increased when the animals were fasted for $88 \mathrm{hr}$. Iysine, threonine, methionine, and arginine content decreased in the rabbit plasina; these amino acids are reported to be decreased in plasma from human subjects fasted for 2 days (13).

\section{REFERENCES}

1. Dechateau, G., and Florkix, M., Arch. intern. physiol. 62, 205 (1954).

2. Exgel, A. F., and Pollak, O. J., Experientia $17,210(1961)$.

3. Stein, W. H., J. Biol. Chem. 201, 45 (1953).

4. Stemx, W. II., Axd Moore, S., J. Biol. Chem. 211, 915 (1954).

5. Spackman, D. H., Steix, W. H., avd Moore, S., Anal. Chem. 30, 1190 (1958).

6. Hubbard, R. W., Steele, B. F., Spear, Y., and Block, W. D., J. Invest of Derm. In Pless.

7. Soupakt, P., Clin. Chim. Acta 5, 235 (1960).

8. Tallay, H. H., Moore, S., and Stem, W. H., J. Biol. Chem. 211,927 (1954).

9. Browx, D. D., Silva, O. L., McDonaln, P. B., Sryder, S. H., ANd Kies, M. W., J. Biol. Chem. 235, $154(1960)$.

10. Fink, K., Williams, A. D., ayd Fink, R. M., J. Biol. Chem. 234, 1182 (1959).

11. MoMarvs, I. R., J. Biol. Chem. 235, 1398 (1960).

12. Swexdseid, M. E., Frindrich, B. W. ANd Tetrte, S. G., Federation Proc. 20, 8 (1961).

13. Charkey, L. W., Kaxo, A. K., and Hougham, D. F... . Nutrition 55, 469 (1955). 